\title{
Flutuação Populacional de Rhizoctonia spp. em Jardim Clonal de Eucalyptus spp.
}

\author{
Eugenio Sanfuentes ${ }^{1}$, Acelino C. Alfenas ${ }^{2}$, Luiz A. Maffia ${ }^{2} \&$ Reginaldo G. Mafia $^{3}$ \\ ${ }^{1}$ Universidad de Concepción, Facultad de Ciencias Forestales, Victoria 631, Concepción, Chile; ${ }^{2}$ Departamento de \\ Fitopatologia, Universidade Federal de Viçosa, CEP 36570-000, Viçosa, MG, Brasil, e-mail: aalfenas@ufv.br; \\ ${ }^{3}$ Aracruz Celulose S.A. Centro de Pesquisa e Tecnologia, CEP 29197-9000, Aracruz, ES, Brasil
}

Autor para correspondência: Acelino C. Alfenas

SANFUENTES, E.A., ALFENAS, A.C., MAFFIA, L.A. \& MAFIA, R.G. Flutuação populacional de Rhizoctonia spp. em jardim clonal de Eucalyptus spp. Fitopatologia Brasileira 32:114-120. 2007.

\begin{abstract}
RESUMO
A queima de folhas em brotações em jardim clonal e a mela de estacas na fase de enraizamento, causadas por espécies de Rhizoctonia, podem limitar a produção de mudas de eucalipto por estaquia. Apesar de sua importância, pouco se conhece sobre essas doenças. Assim, visando otimizar as estratégias de controle dessas doenças, nesse trabalho objetivou-se elucidar aspectos da dinâmica populacional de Rhizoctonia spp. no solo e em brotações, a fim de estabelecer, correlações com a incidência da doença, bem como determinar a distribuição do patógeno em jardim clonal de eucalipto. Conclui-se que há flutuação populacional de Rhizoctonia spp. em jardim clonal de eucalipto, sendo observado um padrão de distribuição espacial agregado do inóculo no solo. A dinâmica populacional de Rhizoctonia spp. foi correlacionada à temperatura, mas não à precipitação pluviométrica.
\end{abstract}

Palavras-chave adicionais: epidemiologia, eucalipto, queima foliar, mela de estacas.

\begin{abstract}
Population fluctuation of Rhizoctonia spp. in clonal nurseries of Eucalyptus spp.

Leaf blight in shoots of clonal hedges and web blight of cuttings for rooting, caused by Rhizoctonia species, may be limiting to the production of eucalyptus seedlings by cuttings. Despite their importance, there have been few etiological and epidemiological studies of these diseases. To optimize disease management strategies, this research aimed to evaluate population dynamics of Rhizoctonia spp. in soil and eucalyptus cuttings to correlate with disease incidence, and to determine spatial distribution of Rhizoctonia spp. inoculum in a clonal nursery of eucalyptus cuttings. Population fluctuation of Rhizoctonia spp. was detected throughout the year. Pathogen distribution in soil was found to have an aggregated pattern. Temperature, but not rainfall, was correlated to population levels of Rhizoctonia spp in soil samples.
\end{abstract}

Additional Keywords: epidemiology, eucalyptus, leaf blight, web blight of cuttings.

\section{INTRODUÇÃO}

A propagação de mudas de eucalipto, por estaquia, permite a implantação de talhões homogêneos, formados por genótipos resistentes a doenças e com características silviculturais superiores. No entanto, as condições ambientais requeridas para induzir o enraizamento de estacas e miniestacas de eucalipto são altamente favoráveis à ocorrência de fungos fitopatogênicos. Dentre esses, destacam-se espécies de Rhizoctonia, que ocorrem em todas as fases da propagação clonal do eucalipto (Alfenas et al., 2004).

A queima de folhas em jardim clonal e a mela de estacas na fase de enraizamento, causadas por Rhizoctonia solani J.G. Kühn AG1-1B e isolados binucleados de Rhizoctonia spp. (Silveira et al., 2000), podem limitar a

Parte da Tese de Doutorado do primeiro autor. Universidade Federal de Viçosa. 2000. produção de mudas de eucalipto por estaquia. Espécies de Rhizoctonia são habitantes naturais do solo, que sobrevivem saprofiticamente, colonizando a matéria orgânica, ou na forma de escleródios (Bouhot, 1979; Bruehl, 1987). Em jardins clonais, brotações são infectadas mediante respingos de água de chuva ou irrigação, contendo partículas de solo infestadas (Ferreira, 1989, 1991), ou via crescimento micelial a partir do solo (Rezende \& Ferreira, 1992). Assim, brotações infectadas passam a constituir fontes de inóculo a estacas para enraizamento.

No sistema de produção de mudas por estaquia, as perdas causadas por Rhizoctonia spp. variam em função do manejo empregado nas diferentes fases da produção de mudas. No jardim clonal, a ocorrência e severidade da queima têm sido associadas, principalmente, ao sistema de coleta de brotações e tipo de irrigação. A coleta de brotos a cada 50-60 dias permite o adensamento de copas, o que favorece a formação e a manutenção de umidade e temperatura favoráveis à infecção e à dispersão secundária do patógeno. Da mesma forma, a irrigação por aspersão 
facilita a dispersão vertical e a horizontal do patógeno.

Considerando as limitações de controle da mela de estacas durante a fase de enraizamento (Silveira et al., 2003), todas as medidas aplicadas durante a produção de brotações em jardim clonal são importantes. Todavia, ainda não se realizaram estudos sobre a quantidade e a distribuição do inóculo de Rhizoctonia spp. no solo, o que impossibilita correlacionar a incidência e severidade da doença à flutuação populacional do patógeno no solo e em brotações do jardim clonal de eucalipto, bem como otimizar as estratégias de controle. Assim, o presente trabalho objetivou elucidar aspectos da dinâmica espacial e temporal de populações de Rhizoctonia spp. no solo e brotações em jardim clonal de eucalipto.

\section{MATERIAL E MÉTODOS}

\section{Caracterização dos locais de estudo}

Os estudos transcorreram em dois jardins clonais de eucalipto. No jardim clonal 1, localizado em Aracruz ES, o solo era de textura franco-arenosa (60\% de areia grossa, $18 \%$ de areia fina, $6 \%$ de silte e $16 \%$ de argila), $\mathrm{pH}=5,0$, matéria orgânica $(\mathrm{MO})=4,62 \mathrm{dag} / \mathrm{kg}$ e capacidade de campo (CC) de 14,6 \% (-0,1 bar). Aárea experimental constituía-se de dois talhões: $1 \mathrm{~A}$, recém-implantado, e 1B, em plena produção de brotos para estaquia por três anos. No jardim clonal 2, localizado em Belo Oriente MG, o solo tinha textura francoargilosa-arenosa (56\% de areia grossa, $11 \%$ de areia fina, $11 \%$ de silte e $16 \%$ de argila), $\mathrm{pH}=4,7, \mathrm{MO}=2,69 \mathrm{dag} / \mathrm{kg}$ e $\mathrm{CC}=$ 18,6 \% (-0,3 bar). A área experimental (talhão 2) tinha cerca de três anos de produção. Durante o monitoramento da flutuação populacional do patógeno no solo e em brotações, coletaramse dados climáticos em estações meteorológicas situadas em ambos os jardins clonais.

\section{Amostragem de solo}

Efetuaram-se amostragens de solo mensalmente, durante 12 meses (fevereiro de 1998 a janeiro de 1999) e 11 meses (maio de 1998 a março de 1999), nos jardins 1 e 2, respectivamente. Para tal, instalaram-se 25 parcelas permanentes de amostragem, distribuídas sistematicamente em 0,64, 0,24 e 0,5 ha, nos talhões $1 \mathrm{~A}, 1 \mathrm{~B}$ e 2, respectivamente. As parcelas foram delimitadas por 10 cepas ( 2 fileiras $x 5$ cepas) (Figura 1). Próximo à base de cada cepa, coletavam-se de 100 a $120 \mathrm{~mL}$ de solo, entre 0 e 7 cm de profundidade, e se constituiu uma amostra composta de cerca de 1,2 L por parcela. As amostras foram acondicionadas em sacolas plásticas e armazenadas a temperatura ambiente por no máximo 5 dias, até sua utilização.

\section{Densidade de inóculo e distribuição espacial do patógeno no solo}

Estimou-se a densidade de inóculo de Rhizoctonia spp. pelo método de colonização de iscas de eucalipto, o qual se baseia na capacidade saprófitica do fungo (Sanfuentes et al., 2002). Empregaram-se amostras de $200 \mathrm{~g}$ de solo, cuja umidade foi ajustada para 125 \% CC (jardim clonal 1) ou $100 \%$ CC (jardim clonal 2). Como iscas biológicas,

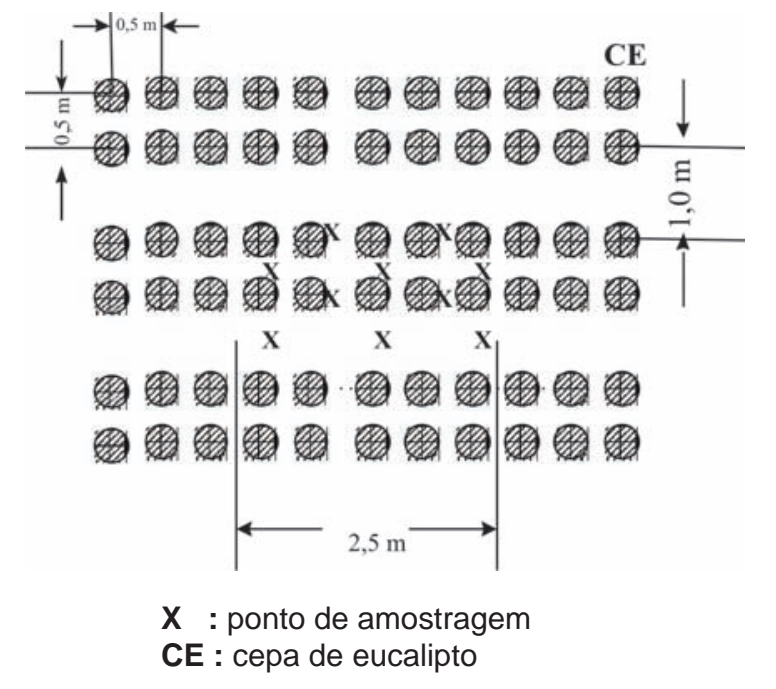

FIG. 1 - Características das parcelas de amostragem.

empregaram-se secções cilíndricas (20 x 5 mm) de hastes de eucalipto. Essas foram desinfestadas superficialmente com $\mathrm{NaClO}$, a $1000 \mathrm{ppm}$ de $\mathrm{Cl}_{2}$ ativo, por $5 \mathrm{~min}$, lavadas com água destilada esterilizada e enterradas no solo, contido em caixas plásticas do tipo gerbox (11 x 11 x $3 \mathrm{~cm}$ ). Após incubação a 27 ${ }^{\circ} \mathrm{C}$, no escuro, por $48 \mathrm{~h}$, as iscas foram retiradas do solo, lavadas em água de torneira por $3 \mathrm{~min}$, desinfestadas com $\mathrm{NaClO}$, por 3 min, enxaguadas por duas vezes com água destilada esterilizada e semeadas em meio de ágar-água $(2 \%)$ acidificado $(\mathrm{pH}=5,0)$. Após 36 a 48 h de incubação a $27^{\circ} \mathrm{C}$, no escuro, avaliou-se sob microscópio de luz (x400), a presença de colônias típicas de Rhizoctonia, crescendo a partir das iscas. Para cada amostra de solo, empregaram-se três repetições, cada uma constituída de um gerbox com 200 g de solo, no qual inseriram-se 30 iscas. Como testemunha, foram empregadas iscas biológicas desinfestadas superficialmente, conforme descrito anteriormente, sem incubação no solo. Os resultados foram expressos em porcentagem de iscas colonizadas pelo patógeno. Adicionalmente, determinou-se a distribuição espacial do patógeno no solo, por meio da razão variância/média (Campbell \& Madden, 1990).

\section{Amostragem de brotações e de estacas para enraizamento}

Simultaneamente à amostragem de solo, avaliaram-se a ocorrência de Rhizoctonia spp. em brotações aparentemente sadias usadas para estaquia (coletaram-se duas brotações aparentemente sadias por cepa, que foram colocadas em sacos de papel e armazenadas a $5^{\circ} \mathrm{C}$ ) e a incidência da mela em estacas coletadas dentro da casa de enraizamento. Nessa avaliação, empregaramse 11 bandejas com 96 tubetes/bandeja e seis bandejas com 176 tubetes/bandeja, nas casas de vegetação dos jardins clonais 1 e 2, respectivamente. Aos 7, 14, 21 e 28 dias do estaqueamento, as estacas com sintomas de mela foram coletadas e armazenadas, conforme descrito anteriormente, até a avaliação. 
Determinação da ocorrência do patógeno em brotações e estacas de eucalipto

As brotações coletadas nos jardins clonais foram distribuídas em caixas tipo gerbox, contendo duas folhas de papel-toalha umedecido com água esterilizada, para formar uma câmara úmida. As caixas foram mantidas em câmara de nevoeiro, a $25^{\circ} \mathrm{C}$, fotoperíodo de 12 h e 1600 Lux. Após 7 dias de incubação, as brotações foram avaliadas ao microscópio estereoscópico, quanto à presença de micélio de Rhizoctonia spp. Confirmou-se a presença do patógeno com preparações e observações microscópicas (x400).

As estacas com sintomas de mela foram lavadas em água de torneira, por 2 a $3 \mathrm{~min}$, desinfestadas superficialmente com $\mathrm{NaClO}$ por 3 min, retirou-se o excesso de cloro por duas passagens em água destilada esterilizada, e semeadas em ágar-água acidificado. Após 48 h de incubação a $26^{\circ} \mathrm{C}$ no escuro, avaliou-se quanto à presença do patógeno, sob microscópio de luz (x400).

\section{RESULTADOS}

Flutuação populacional de Rhizoctonia spp. em solo de jardim clonal

Constatou-seflutuaçãonadensidadedeinóculode Rhizoctonia spp. no solo, ao longo do período experimental, em ambos os jardins clonais (Figuras 2 e 3). Durante todo o ano, no jardim clonal
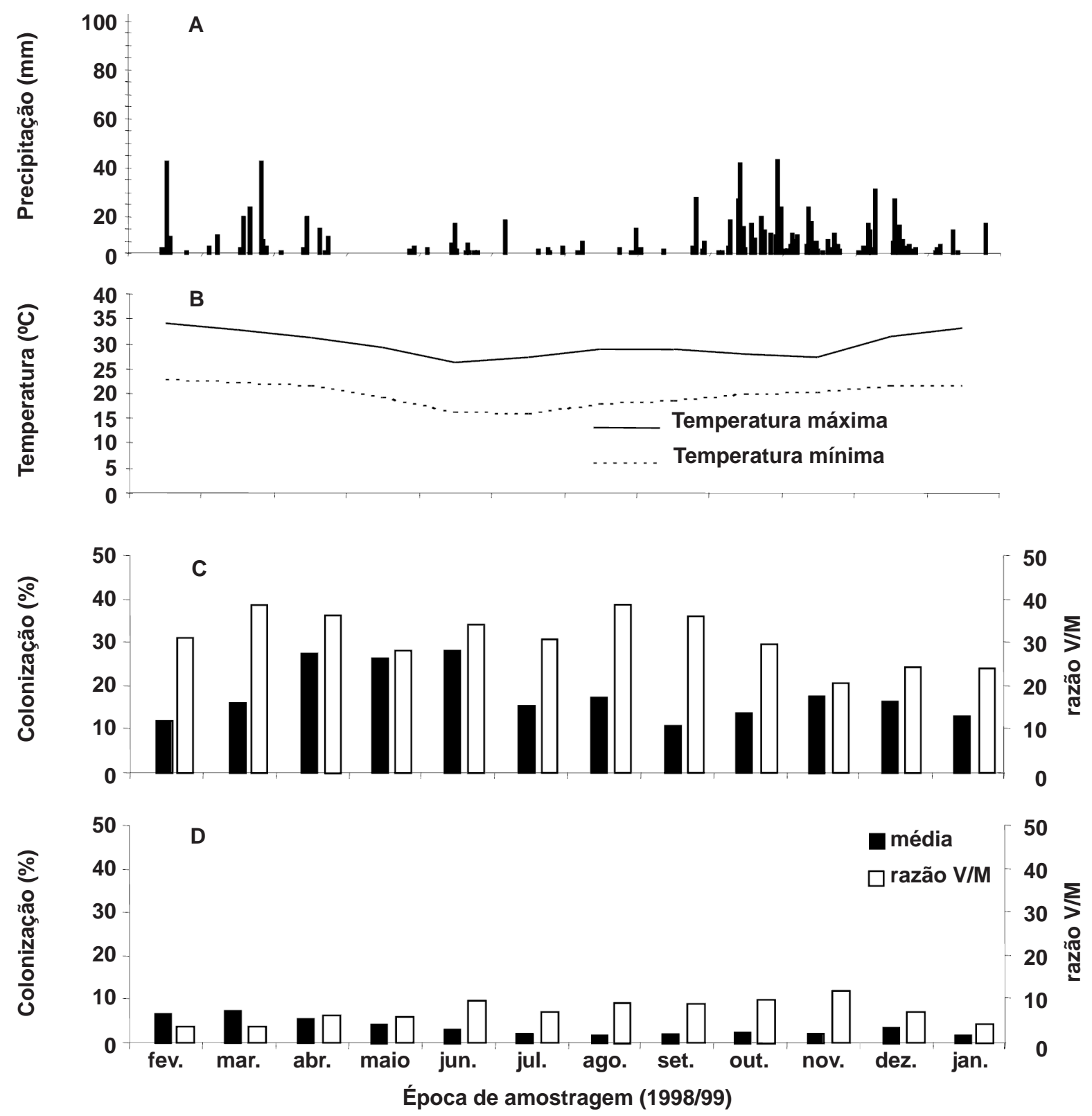

FIG. 2 - A. Precipitação pluviométrica; B. médias mensais de temperatura (máxima e mínima); e porcentagem de colonização de iscas de eucalipto por Rhizoctonia spp., e valores da razão variância/média (VM) para as áreas 1A(C) e 1B (D) do jardim clonal 1 (Aracruz - ES), de fevereiro/1998 a janeiro/1999. 
1, a densidade de inóculo foi maior na área $1 \mathrm{~A}$ que na $1 \mathrm{~B}$ (Figura 2), com um pico entre abril e junho. No jardim clonal 2, o pico na densidade de inóculo ocorreu entre maio e julho (Figura 3). Os isolados obtidos foram caracterizados como pertencentes a diferentes espécies de Rhizoctonia (Sanfuentes, 2000).

Nas três áreas, não se detectou correlação entre a densidade de inóculo do patógeno no solo e a precipitação pluviométrica avaliada aos 7, 15 e 30 dias antes da amostragem de solo (Figuras 2 e 3). Na área 1A, houve tendência de relação inversa entre a densidade de inóculo e as temperaturas média e máxima, mas a correlação não foi significativa. Nas áreas $1 \mathrm{~B}$ e 2, houve correlação significativa da densidade de inóculo e a temperatura avaliada aos 15 e 30 dias antes da amostragem de solo. Para a área 1B, os valores do coeficiente de correlação foram positivos e, para a 2, negativos (Tabela 1).

Nas três áreas obtiveram-se valores da razão variância/média sempre maiores que 1,0 (Figuras 2 e 3), o que sugere distribuição agregada do inóculo de Rhizoctonia spp., que estava concentrado em dois a três focos/área, segundo observação de mapas das áreas.

\section{Ocorrência do patógeno em brotações e em estacas para enraizamento}

Em geral, a ocorrência de Rhizoctonia spp. nas brotações coletadas foi baixa. Na área 1A, constataram-se de 1 a 4 brotações infectadas nos meses de maior densidade de inóculo do fungo no solo, março a outubro; na 1B, constatouse somente uma brotação infectada, em junho, e, na 2, não se detectaram brotações infectadas.

Os isolados obtidos foram caracterizados como pertencentes a diferentes espécies de Rhizoctonia. Em geral, além de Rhizoctonia spp. sob brotações, outros fungos, tanto saprófitas como patogênicos, ocorreram em freqüência alta nas folhas de eucalipto, espécies de Alternaria, Aspergillus, Botrytis, Colletotrichum, Cladosporium, Epicoccum, Hainessia, Fusarium, Penicillium, Pestalotiopsis e Puccinia.

No jardim clonal 1, a incidência de Rhizoctonia
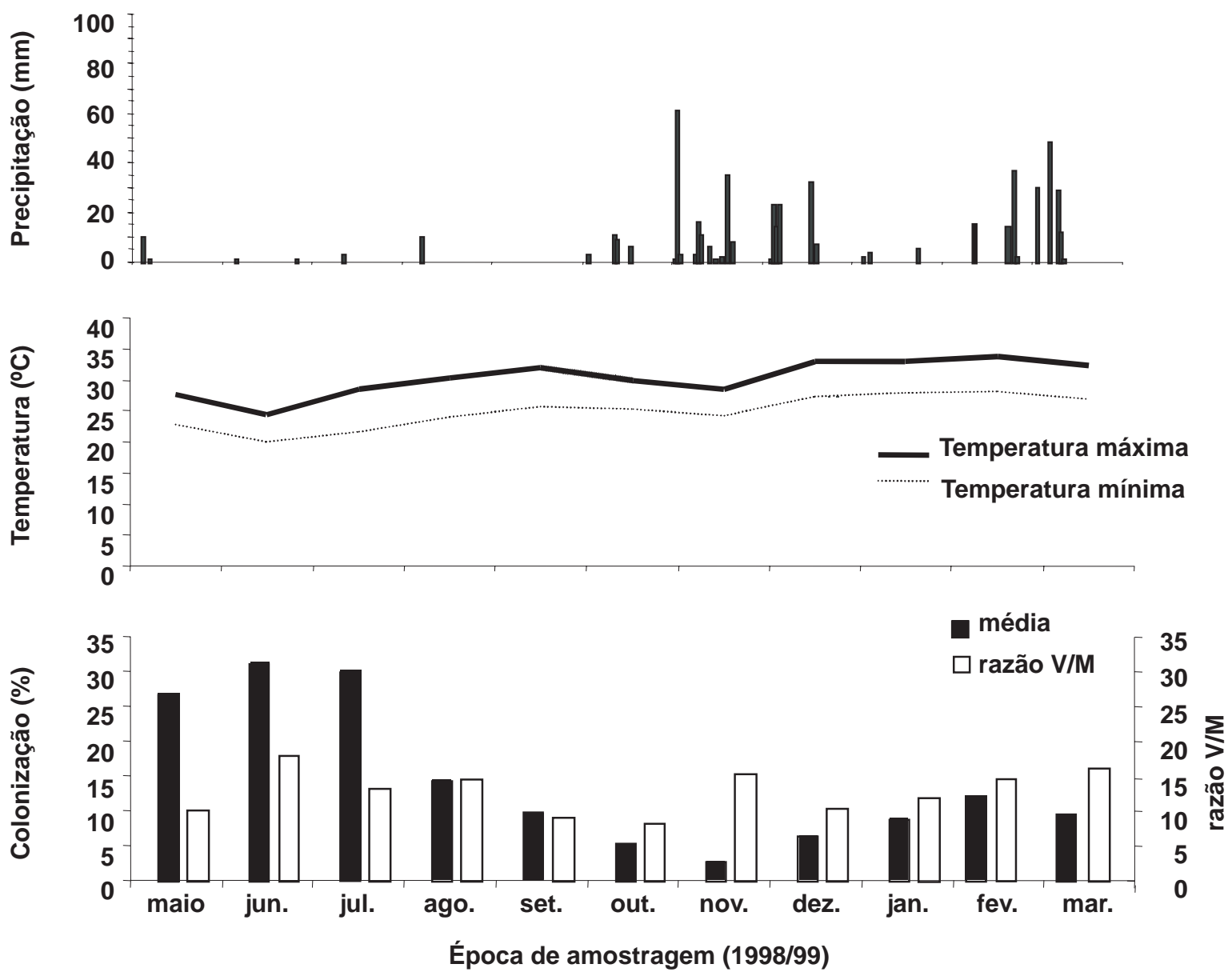

FIG. 3 - A. Precipitação pluviométrica; B. médias mensais de temperatura (máxima e mínima); porcentagem de colonização de iscas de eucalipto por Rhizoctonia spp. e valores da razão variância/ média (VM) (C) para o jardim clonal 2 (Belo Oriente MG), durante de maio/1998 a março/1999. 
TABELA 1 - Coeficientes de correlação de Pearson (R) da densidade de inóculo de Rhizoctonia spp. às temperaturas máxima e média, avaliadas aos 7, 15 ou 30 dias antes da amostragem do fungo, nas áreas experimentais 1 A e B (Aracruz, ES) e 2 (Belo Oriente MG)

\begin{tabular}{lcccc}
\hline \multirow{2}{*}{$\begin{array}{c}\text { Temperatura } \\
\left({ }^{\mathbf{C}} \mathbf{C}\right)\end{array}$} & $\begin{array}{c}\text { Dias antes da } \\
\text { amostragem }\end{array}$ & $\mathbf{1 A}$ & \multicolumn{3}{c}{ AB } & $\mathbf{2}$ \\
\cline { 2 - 5 } Média & 7 & -0.423 & 0,489 & $-0,829^{* *}$ \\
& 15 & -0.309 & $0,635^{*}$ & $-0,810^{* *}$ \\
& 30 & -0.259 & $0,684^{* *}$ & $-0,879^{* *}$ \\
Máxima & 7 & -0.291 & 0,454 & $-0,627^{*}$ \\
& 15 & $-0,300$ & $0,592^{*}$ & $-0,690^{*}$ \\
& 30 & $-0,269$ & $0,686^{* *}$ & $-0,856^{* *}$ \\
\hline
\end{tabular}

*ou **: R significativo ao nível de 1 ou $5 \%$ de probabilidade, respectivamente.

em estacas na casa de enraizamento não ultrapassou $0,3 \%$. No jardim clonal 2, a mortalidade de estacas foi no máximo 4,3\%, em setembro, e não foi maior que $0,6 \%$ nas outras épocas. A mortalidade total de estacas oscilou entre 4,2\% e 5,9\%.

\section{DISCUSSÃO}

Em todas as áreas estudadas, houve flutuação na atividade saprofítica ou densidade de inóculo de Rhizoctonia spp. no solo. Não há estudos sobre a dinâmica populacional de Rhizoctonia spp. em sistemas florestais. Em um cultivo de feijão em rotação com centeio, a atividade saprofítica de $R$. solani variou com a incorporação de restos culturais no solo e com o plantio da planta suscetível (Papavizas et al., 1975). Estes autores observaram que há declínio gradual da população do patógeno durante o inverno e a primavera, o que foi associado à redução gradual de fontes de nutrientes em vista da decomposição, como também às baixas temperaturas que limitaram o crescimento do fungo no solo. Os autores sugeriam alta dependência de $R$. solani à existência de fontes de nutrientes disponíveis. Nos jardins clonais de eucalipto, como não ocorreu incorporação de restos de poda, acredita-se que outras variáveis tenham determinado a dinâmica populacional do fungo no solo.

A dinâmica populacional do patógeno no solo não foi afetada pelo regime de chuvas das regiões em estudo, o que provavelmente deveu-se às freqüentes irrigações por aspersão. Nesse caso, há maior intensidade de irrigações nos períodos mais secos do ano, para manter a umidade do solo o mais estável possível. A resposta à temperatura foi diferenciada e dependeu do local do estudo e da idade do jardim clonal. $\mathrm{Na}$ área $1 \mathrm{~A}$, os valores dos coeficientes de correlação da temperatura e a população de Rhizoctonia spp. foram negativos, mas não significativos. $\mathrm{Na}$ área $1 \mathrm{~B}$, com menor quantidade de inóculo, o aumento da população do fungo correlacionou-se ao aumento das temperaturas médias e máximas. Na área 2, ocorreu maior quantidade de inóculo no solo no intervalo de maio a julho, período mais frio do ano. Com esses resultados reforça-se a necessidade de conhecimentos mais detalhados sobre a microbiota de solos florestais, para os quais estudos poliéticos são indispensáveis.
As variações na temperatura do solo provavelmente afetaram a sobrevivência e, principalmente, o crescimento de Rhizoctonia spp. e/ou beneficiaram organismos antagônicos aos fungos. Espécies de Trichoderma e Gliocladium podem exercer atividade antagônica ao patógeno em solo ou em substrato de crescimento de plantas (Nelson et al., 1983; Nelson \& Hoitink, 1983; Stephens et al., 1981; Chung et al., 1988; Kuter et al., 1988; Hardy \& Sivasithamparam, 1995; Tuiter et al., 1998; Kunieda-Alonso et al., 2005). Ademais, pode ter ocorrido seleção de isolados de Rhizoctonia, após determinado tempo de estabelecimento do jardim clonal, capazes de se desenvolverem em condições diferenciadas. Há variações entre isolados de Rhizoctonia, os quais formam grupos e sub-grupos com diferentes comportamentos ecológicos e epidemiológicos (Ogoshi, 1987). Neste sentido, Martin (1988) observou mudanças na freqüência de isolados binucleados, durante um ano, em morangueiro: isolados AG-G e AG-A predominaram sobre isolados AG-I, provavelmente pela redução da temperatura ou pela resposta a diferentes exsudatos radiculares.

A maior quantidade de inóculo na área $1 \mathrm{~A}$ que na 1B merece atenção, especialmente em futuros estudos de dinâmica populacional de Rhizoctonia spp. A única diferença entre essas áreas diz respeito ao tempo de implantação do jardim clonal, pois outros fatores (tipo de solo e manejo das cepas) foram idênticos. Nesse período de aproximadamente três anos, podem ter havido mudanças quantitativas e qualitativas na população de Rhizoctonia spp. Provavelmente, isolados de Rhizoctonia spp. que possuem maior capacidade de sobreviver em associação ou causando doença em plantas daninhas, normalmente presentes no jardim clonal, podem manter sua população ou aumentá-la em relação a outros tipos de isolados de Rhizoctonia spp. Além desse fator, a diferença na densidade populacional inicial entre as áreas pode estar relacionada com a variação detectada.

Durante o período avaliado, atribuiu-se a baixa incidência da queima foliar nos jardins clonais em estudo à baixa quantidade de inóculo de isolados específicos de Rhizoctonia spp. no solo, capazes de se desenvolverem na parte aérea. Acredita-se que Rhizoctonia spp. sejam dispersas por meio de respingos de água de chuva ou irrigação, 
contendo partículas de solo infestadas com o patógeno (Ferreira, 1989), ou via crescimento epifítico (Rezende \& Ferreira, 1992). É necessário determinar se os isolados do patógeno que causam doença na parte aérea podem crescer do solo até a parte aérea ou são dispersos por respingos de água.

Nas épocas de maior densidade de inóculo no solo do jardim clonal 2, dentro da casa de enraizamento houve mortalidade de estacas de eucalipto. Todavia, acredita-se que a maior quantidade de inóculo de Rhizoctonia spp. no solo, em determinada época, não necessariamente implicará em maior ocorrência da mela de estacas durante o enraizamento. A falta de correlação entre a quantidade de propágulos de Rhizoctonia e intensidade da doença pode estar relacionada à heterogeneidade de isolados com diferentes graus de virulência (Martin et al., 1983), às condições que favorecem a dispersão do patógeno do solo para a parte aérea e à freqüência de isolados capazes de crescer do solo e atingir a parte aérea. Entretanto, Belmar et al. (1987) verificaram alta correlação entre o número de escleródios de $R$. solani AG1-A e a incidência de queima da bainha no arroz durante o início da formação da panícula.

Tem-se determinado o nível populacional de Rhizoctonia por métodos que variam desde a quantificação direta dos propágulos no solo ao uso de técnicas imunológicas (Van Bruggen, 1986). Todavia, pelo uso de iscas biológicas, não é possível discriminar isolados patogênicos dos nãopatogênicos ao eucalipto, nem os isolados com capacidade de crescer até a parte aérea dos demais isolados presentes no solo. Por isso, acredita-se também que, no presente estudo, não se constatou doença em níveis elevados em brotações ao mesmo tempo e nos locais (áreas 1A e 2) em que se quantificaram altas populações do patógeno no solo.

Foram detectados vários fungos saprófitas e patogênicos em folhas de eucalipto, o que pode ter afetado a eficiência de detecção do patógeno, especialmente quando ainda não ocorreu a infecção. Sendo assim, devem-se aprimorar os métodos que favoreçam o isolamento seletivo do patógeno.

Em todas as áreas estudadas, a distribuição espacial do inóculo de Rhizoctonia estava de forma agregada, considerando a razão V/M e o mapeamento do inóculo (Sanfuentes, 2000). A distribuição agregada de inóculo de Rhizoctonia spp., já relatada por vários autores (Martin et al., 1983; Belmar et al.,1987; Yang et al., 1991; Macnish et al., 1993), pode ser atribuída às condições de microssítios que determinam o aumento ou a redução do inóculo em certas áreas (Martin et al., 1983). Fatores bióticos e/ou abióticos podem também influenciar a densidade de inóculo do fungo. Temperatura, umidade, fatores edáficos $\mathrm{e}$ a microbiota antagônica podem não ser uniformes no campo, o que determina os diferentes níveis de inóculo do fungo. $\mathrm{O}$ conhecimento da distribuição espacial do inóculo no jardim clonal tem valor prático no manejo da doença, por permitir o direcionamento de medidas específicas de controle nas áreas focos, para evitar a dispersão do patógeno. Esse aspecto pode ser importante, principalmente quando se considera a movimentação de solo durante o preparo do jardim clonal. Entretanto, o conhecimento do tipo e grau de agregação do inóculo no solo terá valor limitado, se não se conhecerem os tipos de isolados que constituem a população de Rhizoctonia spp., especialmente aqueles relacionados às doenças da parte aérea, de características e requerimentos distintos de outros isolados habitantes do solo.

Com os resultados desse trabalho, concluiu-se que há flutuação populacional de Rhizoctonia spp. em jardim clonal de eucalipto, com distribuição espacial do inóculo no solo do tipo agregado. A temperatura, diferentemente da precipitação pluviométrica, afetou a dinâmica populacional do patógeno. Demanda-se mais estudos relacionados à dinâmica populacional de espécies de Rhizoctonia patogênicas ao eucalipto, para melhor embasamento de estratégias de manejo da queima de folhas em brotações em jardim clonal e a mela de estacas na fase de enraizamento do eucalipto.

\section{AGRADECIMENTOS}

O primeiro autor agradece à CAPES pela concessão de bolsa de estudos no programa PEC/PG.

\section{REFERÊNCIAS BIBLIOGRÁFICAS}

ALFENAS, A.C., ZAUZA, E.A.V., MAFIA, R.G. \& ASSIS, T.F. Clonagem e doenças do eucalipto. Editora UFV. 2004.

BELMAR, S.B., JONES, R.K. \& STARR, J.L. Influence of crop rotation on inoculum density of Rhizoctonia solani and sheath blight incidence in rice. Phytopathology 77:1138-1143. 1987.

BOUHOT, D. Estimation of inoculum density and inoculum potencial: techniques and their value for disease prediction. In: Schippers, B. \& Gams, W. (Eds.) Soil-Borne Plant Pathogens. Oxford. Academic Press. 1979.

BRUEHL, G.W. Soilborne plant pathogens. New York NY. Mac Millan Publishing Company. 1987.

CAMPBELL, C. \& MADDEN, L. Introduction to plant disease epidemiology. New York NY. John Willey \& Sons. 1990.

CHUNG, Y.R., HOITINK, H.A.J., DICK, W.A. \& HERR, L.J. Effects of organic matter decomposition level and cellulose amendment on the inoculum potencial of Rhizoctonia solani in hardwood bark media. Phytopathology 78:836-840. 1988.

FERREIRA, F.A. Patologia florestal: principais doenças florestais no Brasil. Viçosa MG. Sociedade de Investigações Florestais. 1989.

FERREIRA, F.A. Queima foliar do eucalipto por Rhizoctonia solani em jardim clonal e plantas no campo na região amazônica. Fitopatologia Brasileira 16:36. 1991.

HARDY, G.E. \& SIVASITHAMPARAM, K. Antagonism of fungi and actinomycetes isolated from composted eucalyptus bark to Phytophthora drechsleri in steamed and non-steamed composted 
eucalyptus bark-amended medium. Soil Biology and Biochemistry 27:243-246. 1995.

KUNIEDA-ALONSO, S., ALFENAS, A.C. \& MAFFIA, L.A. Sobrevivência de micélio e escleródios de Rhizoctonia solani tratados com Trichoderma spp., em restos de cultura de Eucalyptus sp. Fitopatologia Brasileira 30:164-168. 2005.

KUTER, G.A., HOITINK, H.A.J. \& CHEN, W. Effects of municipal sludge compost curing time on supression of Pythium and Rhizoctonia spp. diseases of ornamental plants. Plant Disease 72:751-756. 1988.

MACNISH, G.C., CARLING, D.E. \& BRAINARD, K.A. Characterization of Rhizoctonia solani AG-8 from bare patches by pectic isozyme (zymogram) and anastomosis techniques. Phytopathology 83:922-927. 1993.

MARTIN, S.B. Identification, isolation frequency, and pathogenecity of anastomosis groups of binucleate Rhizoctonia spp. from strawberry roots. Phytopathology 78:379-384. 1988.

MARTIN, S.B., CAMPBELL, C.L. \& LUCAS, L.T. Horizontal distribution and characterization of Rhizoctonia spp. in tall fescue turf. Phytopathology 73:1064-1068. 1983.

NELSON, E.B. \& HOITINK, H.A.J. The role of microorganisms in the suppression of Rhizoctonia solani in container amended media with composted hardwood bark. Phytopathology 73:274-278. 1983.

NELSON, E.B., KUTER, G.A. \& HOITINK, H.A.J. Effects of fungal antagonists and compost age on suppression of Rhizoctonia spp. damping-off in container media amended with compost hardwood bark. Phytopathology 73:1457-1462. 1983.

OGOSHI, A. Ecology and pathogenicity of anastomosis and intraepecific groups of Rhizoctonia solani Kühn. Annual Review of Phytopathology 25:125-143. 1987.

PAPAVIZAS, G.C., ADAMS, P.B., LUMDSEN, R.D., LEWIS, J.A., DOW, L.R., AYERS, W.A. \& KANTZES, J.G. Ecology and epidemiology of Rhizoctonia solani in field soil. Phytopathology
65:871-877. 1975.

REZENDE, D.V. \& FERREIRA, F.A. Epifitismo de linhagens de Rhizoctonia solani na doença queima de folhas de eucalipto. Fitopatologia Brasileira 17:204. 1992.

SANFUENTES, E.A. Caracterização de isolados, flutuação populacional e controle biológico de Rhizoctonia em jardim clonal de Eucalyptus. Tese de Doutorado. Viçosa MG. Universidade Federal de Viçosa. 2000.

SANFUENTES, E., ALFENAS, A.C., MAFFIA, L.A. \& SILVEIRA, S.F. Comparison of baits to quantify inoculum density of Rhizoctonia spp. in Eucalyptus clonal garden soils. Australasian Plant Pathology 31:177-183. 2002.

SILVEIRA, S.F., ALFENAS, A.C., FERREIRA, F.A. \& SUTTON, J.C. Characterization of Rhizoctonia species associated with foliar necrosis and leaf scorch of clonally-propagated Eucalyptus in Brazil. European Journal of Plant Pathology 106:27-36. 2000.

SILVEIRA, S.F., ALFENAS, A.C., MAFFIA, L.A. \& SUZUKI, M.S. Controle químico da queima de folhas e da mela de estacas de eucalipto, causadas por Rhizoctonia spp. Fitopatologia Brasileira 28:642-649. 2003.

STEPHENS, C.T., HERR, L.J., HOITINK, H.A.J. \& SCHMITTHENER, A.F. Suppression of Rhizoctonia spp. dampingoff composted hardwood bark medium. Plant Disease 65:796-707. 1981.

TUITER, G., SZSCZECH, M. \& BOLLEN, G.J. Suppression of Rhizoctonia solani in potting mixtures amended with compost made from organic household waste. Phytopathology 88:764-773. 1998.

VAN BRUGGEN, A.H.C. Quantitative recovery of Rhizoctonia solani from soil. Plant disease 70:320-323.1986.

YANG, X.B., SNOW, J.P. \& BERGGREN, G.T. Patterns of Rhizoctonia foliar blight on soybean and effect of aggregation on disease development. Phytopathology 81:287-293. 1991. 